\title{
Interest of Serum-Ascites Albumin Concentration Gradient in the Diagnosis of Portal Hypertension in Cirrhotic Patients
}

\author{
Laté Mawuli Lawson-Ananissoh ${ }^{1 *}$, Aklesso Bagny'1, Oumboma Bouglouga'2, \\ Ismael Mahaman Salissou Ganbobo', Rafiou El-Hadji Yakoubou', Lidawu Kogoe', \\ Laconi Kaaga', Datouda Redah'1
}

\author{
${ }^{1}$ Hepatogastroenterology Unit, University Hospital Campus, Lome, Togo \\ ${ }^{2}$ Hepatogastroenterology Unit, University Hospital of Kara, Kara, Togo \\ Email: ^lawsonprosper@yahoo.fr
}

\begin{abstract}
How to cite this paper: Lawson-Ananissoh, L.M., Bagny, A., Bouglouga, O., Ganbobo, I.M.S., El-Hadji Yakoubou, R., Kogoe, L., Kaaga1, L. and Redah, D. (2019) Interest of Serum-Ascites Albumin Concentration Gradient in the Diagnosis of Portal Hypertension in Cirrhotic Patients. Open Journal of Gastroenterology, 9, 13-21.

https://doi.org/10.4236/ojgas.2019.91003
\end{abstract}

Received: December 21, 2018

Accepted: January 15, 2019

Published: January 18, 2019

Copyright $\odot 2019$ by author(s) and Scientific Research Publishing Inc. This work is licensed under the Creative Commons Attribution International License (CC BY 4.0).

http://creativecommons.org/licenses/by/4.0/

\begin{abstract}
Objective: To find a more accessible and less restrictive mean such as serum-ascites albumin gradient (SAAG) to predict esophageal varices (EV) in cirrhotics with ascit. Patients and methods: Descriptive and analytical studies based on the retrospective collection of data on 125 patients' records in the hepatogastroenterology unit of the University Hospital Campus of Lome (Togo) from January 1, 2008 to March 31, 2018 were included. Cirrhotic patients aged 15 years and older had performed cytochemical analysis of ascites fluid and upper gastrointestinal fibroscopy and had a protidogram. Statistical analysis was done by $\mathrm{R}$ Studio Software 3.4.2. Results: The mean age was 48.70 years; there was a male predominance (70.40\%) with a sex ratio of 2.38. Protein levels in ascitic fluid was $<30 \mathrm{~g} / \mathrm{l}$ in $88.80 \%$ of patients. EV were found in $64.80 \%$ of cases. The median SAAG was $1.40 \mathrm{~g} / \mathrm{dl}$. EV were significantly more frequent in case of high SAAG $\geq 1.10$ $\mathrm{g} / \mathrm{dl}, \mathrm{p}=0.0208$. There was no correlation among SAAG and the grade of EV, red signs, gastric varices and portal hypertension gastropathy. Patients with SAAG $\geq 1.10 \mathrm{~g} / \mathrm{l}$ had 1.63 times the risk of having EV (95\% CI $0.63-4.15, \mathrm{p}=$ 0.3020 ). At the threshold of $0.91 \mathrm{~g} / \mathrm{dl}$, the sensitivity was $83.95 \%$ and the specificity $40.90 \%$; the area under the ROC curve was 0.61 . Conclusion: Our study noted that at an upper threshold of $1.10 \mathrm{~g} / \mathrm{dl}$, the SAAG significantly predicted the presence of EV.
\end{abstract}

\section{Keywords}

Esophageal Varices, Serum-Ascit Albumin Gradient, Cirrhosis, Togo 


\section{Introduction}

Cirrhosis is the final stage of any chronic liver disease. Gastrointestinal bleeding by rupture of esophageal varices (EV) is one of the most feared complications of cirrhosis because of its high mortality. All patients with cirrhosis should undergo endoscopic screening at the time of diagnosis to identify those at high risk of bleeding who may benefit from primary prophylaxis [1]. Upper gastrointestinal fibroscopy (UGF) is a relatively expensive, invasive and restrictive practice [2]. In Africa, and in Togo in particular, the follow-up of cirrhotic patients by UGF remains a challenge for clinicians because of the absence or insufficiency of digestive endoscopy units [3]. The appearance of ascite is the most common complication during cirrhosis [4]. The serum-ascites albumin gradient (SAAG) is a minimally invasive method that is very precise, already described as allowing to classifying the ascites fluid according to the absence or the presence of a portal hypertension (PHT) [5] [6] [7]. According to Starling, SAAG is the best indicator of PHT [2] [8] and several studies have shown that there is a direct relationship between SAAG and the different measures of PHT [6] [9]. Studies on non-invasive methods of EV including platelet ratio and spleen diameter have been conducted in african cirrhotic subjects [10] [11]. In Ivory Coast, a study evaluating SAAG and the endoscopic parameters in 2015 showed a link between a high threshold of SAAG and the presenceof EV [12]. The use of SAAG can be considered as an indirect parameter for the detection of EV and be useful in regions where there is a shortage of human and material resources for the realization of the UGF. This study was conducted to find a more accessible and less restrictive mean such as SAAG to predict EV in cirrhotics with ascit.

\section{Patients and Methods}

This was a descriptive and analytical study of data from the hospitalized patient's records in the hepatogastroenterology unit of the Campus University Hospital Center conducted from January 1, 2008 to March 31, 2018 (10 years and 3 months). Included were ascitic cirrhotic patients over the age of 15 who had performed cytochemical analysis of ascites fluid and UGF and had a protidogram. Patients hospitalized for degenerate cirrhosis were not included. SAAG was calculated by the following formula: SAAG $(\mathrm{g} / \mathrm{dl})=[$ Albuminemia $(\mathrm{g} / \mathrm{l})$ - Ascites fluid protein ratio $(\mathrm{g} / \mathrm{l})] / 10$. Normal albuminemia is between 30 and $40 \mathrm{~g} / \mathrm{l}$. The low SAAG was SAAG $<1.10 \mathrm{~g} / \mathrm{dl}$ (exudate); high SAAG was SAAG $\geq 1.10 \mathrm{~g} / \mathrm{dl}$ (transudate). A protein content in the ascites fluid $<30 \mathrm{~g} / 1$ corresponded to a transudate and $\geq 30 \mathrm{~g} / \mathrm{l}$, corresponded to an exudate. The UGF has allowed according to the French classification based on that of the Japanese research company on portal hypertension [13] to diagnose the presence of EV, PHT gastropathy orcardio-tuberosity varices, and specify the grade of EV (I, II, and III) and objectify the presence of red signs. The statistical analysis was performed with the $\mathrm{R}$ Studio software version 3.4.2. The statistical tests used were the Pearson Chi-square test or the Fisher's exact test for qualitative 
variables and the Student's test for quantitative variables. A univariate and multivariate logistic regression was performed to investigate the factors associated with EV. The dependent variable was the existence of a PHT sign coded as 1 if the patient presented endoscopic signs of PHT (EV, cardio-tuberosity varices or PHT gastropathy) and 0 if not. The SAAG variable was the main exposure variable. In the absence of significance, we adjusted the final model to this variable. The variables statistically associated with the endoscopic signs of PHT during the univariate analysis with a degree of significance $\mathrm{p}<0.25$ were introduced in the initial model. Multivariate analysis made it possible to estimate the Adjusted Coast Ratio (aCR) and its 95\% confidence interval (CI) for each selected variable. The adequacy of the model has been verified, based on the $\mathrm{R}^{2}$ value. Patients who did not die during the data collection phase, had given their oral consent for the completion of this study.

\section{Results}

Of 1416 hospitalized cirrhotic patients, 125 medical records were included.

\subsection{Characteristics of Cirrhotic Patients}

The average age was $48.70 \pm 14.89$ years (extremes 15 to 85 years). The most represented age group was 36 to 54 years old. There was a male predominance (70.40\%, male/female sex ratio of 2.38). Ascites fluid was transudative in 111 patients $(88.80 \%)$. Albuminemia $<35 \mathrm{~g} / \mathrm{l}$ was noted in $92.80 \%$ of cases The median SAAG was $1.40 \mathrm{~g} / \mathrm{dl}$. Thrombocytopenia was noted in 75 patients $(60 \%)$. Esophageal varices were observed in 81 patients (64.6\%). Child Pugh B and C scores were noted in $62 \%$ and $29 \%$ of cases. The main causes of cirrhosis were hepatitis B and C viruses (63.60\%) and alcohol (14.40\%).

\subsection{SAAG and Presence of EV}

Esophageal varices were more frequent in case of high SAAG $\geq 1.10 \mathrm{~g} / \mathrm{dl}, \mathrm{p}=$ 0.0208 (Table 1).

\subsection{SAAG and Other Endoscopic Parameters of Portal Hypertension}

There was no association between SAAG and EV grade, red signs,

Table 1. Serum-ascites albumin gradient (SAAG) and presence of esophageal varices.

\begin{tabular}{|c|c|c|c|c|c|}
\hline \multirow[b]{2}{*}{ SAAG } & \multicolumn{2}{|c|}{$\begin{array}{c}\text { Absence of esophageal } \\
\text { varices }\end{array}$} & \multicolumn{2}{|c|}{$\begin{array}{c}\text { Presence of esophageal } \\
\text { varices }\end{array}$} & \multirow{2}{*}{$\begin{array}{l}\mathrm{p} \text { value } \\
0.0208^{++}\end{array}$} \\
\hline & $\mathrm{n}$ & $\%$ & $\mathrm{n}$ & $\%$ & \\
\hline$<1.10 \mathrm{~g} / \mathrm{dl}$ & 21 & 47.73 & 22 & 27.16 & \\
\hline$\geq 1.10 \mathrm{~g} / \mathrm{dl}$ & 23 & 52.27 & 59 & 72.84 & \\
\hline
\end{tabular}


cardio-tuberosity varices (VCT) and PHT gastropathy (Table 2).

\subsection{SAAG and Ascitic Fluid Chemistry}

There was an association between high SAAG $(\geq 1.10 \mathrm{~g} / \mathrm{dl})$ and transudative ascites fluid, and between low SAAG $(<1.10 \mathrm{~g} / \mathrm{dl})$ and exudative ascites fluid $(\mathrm{p}<$ $0.0001)$.

\subsection{Predictive Factors of Esophageal Varices (Univariate Analysis)}

The predictive factors for EV were mainly high vs low SAAG (OR $=2.45,95 \%$ CI [1.14 - 5.32], $\mathrm{p}=0.0223)$, and a SAAG threshold of $1.50 \mathrm{~g} / \mathrm{dl}(\mathrm{OR}=2.42,95 \%$ CI [1.14 - 5.27], $\mathrm{p}=0.0232$ ) as shown in Table 3.

\subsection{Predictive Factors of Esophageal Varices (Multivariate Analysis)}

After adjustment on sex, protein content in ascites fluid and platelet count, patients with SAAG $\geq 1.01 \mathrm{~g} / \mathrm{dl}$ had 1.63 (95\% CI [0.63 - 4.15]) times the risk of having EV $(\mathrm{p}=0.3020)$. Being male $(\mathrm{OR}=2.7195 \%$ CI [1.09 - 6.88], $\mathrm{p}=0.0321)$, having a protein level in ascites fluid $<30 \mathrm{~g} / \mathrm{l}(\mathrm{OR}=12.7795 \% \mathrm{CI}$ [2.71 - 94.24], $\mathrm{p}=0.0033)$ and thrombocytopenia $(\mathrm{OR}=4.3095 \%$ CI $[1.83-10.47], \mathrm{p}=$ 0.0010), predisposed to having EV (Table 4).

\subsection{Diagnostic Performance of SAAG for the Prediction of Esophageal Varices}

At the threshold of $1.1 \mathrm{~g} / \mathrm{dl}$, the sensitivity (Se) was $72.83 \%$, the specificity (Spe) was $47.72 \%$; the positive predictive value (PPV) was $71.6 \%$. When SAAG $\leq 0.02$ $\mathrm{g} / \mathrm{dl}$, Se was $100 \%$ and Spe $\leq 18.16 \%$. When SAAG $\geq 3.16 \mathrm{~g} / \mathrm{dl}$, Spe was $100 \%$ and $\mathrm{Se} \leq 1.23 \% .0 .91 \mathrm{~g} / \mathrm{dl}$ corresponded to the Youden index (better sensitivity, better specificity), with Spe of $40.90 \%$ and Se of $83.95 \%$. The area under the curve was

Table 2. Serum-ascites albumin gradient (SAAG) and other endoscopic parameters of portal hypertension.

\begin{tabular}{ccccc}
\hline & \multicolumn{3}{c}{ SAAG } & \multirow{2}{*}{ p value } \\
\cline { 2 - 4 } & $<1.10$ & {$[1.10-1.49]$} & $\geq 1.50$ & \\
\hline Red signs & $9(20.93)$ & $3(13.64)$ & $16(26.67)$ & $0.4913^{++}$ \\
Cardio-tuberosity varices & $0(0.00)$ & $0(0.00)$ & $1(1.67)$ & $0.9999^{++}$ \\
PHT $^{\text {a }}$ gastropathy & $20(50.00)$ & $9(40.91)$ & $27(46.55)$ & $0.7898^{+}$ \\
EV $^{\mathrm{b}}$ Grade & & & & $0.1839^{++}$ \\
I & $2(9.09)$ & $2(14.28)$ & $9(19.56)$ & \\
II & $12(54.54)$ & $10(71.44)$ & $17(37.78)$ & \\
III & $8(36.37)$ & $2(14.28)$ & $19(41.31)$ & \\
Presence of $\mathrm{EV}^{\mathrm{b}}$ & $22(51.16)$ & $14(63.64)$ & $45(75.00)$ & $0.0438^{+}$ \\
\hline
\end{tabular}

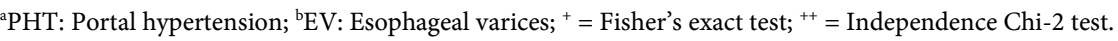


Table 3. Predictive factors of esophageal varices (univariate analysis).

\begin{tabular}{cccc}
\hline & OR & $95 \%$ CI & p value \\
\hline Male vs. female & 1.92 & {$[0.87-4.25]$} & 0.1052 \\
Albuminemia $(\mathrm{g} / \mathrm{l}) \geq 35$ vs. $<35$ & 1.68 & {$[0.37-11.82]$} & 0.5363 \\
Albumin in ascites fluid $(\mathrm{g} / \mathrm{l})<30$ vs. $\geq 30$ & 14.81 & {$[3.77-98.69]$} & 0.0007 \\
Child C vs. A and B & 2.95 & {$[1.22-7.96]$} & 0.0222 \\
SAAG (g/dl) $\geq 1.1$ vs. $<1.1$ & 2.45 & {$[1.14-5.32]$} & 0.0223 \\
Age (years) $<50$ vs. $\geq 50$ & 1.17 & {$[0.56-2.46]$} & 0.6747 \\
Alcohol yes vs. no & 2.66 & {$[1.04-6.93]$} & 0.0406 \\
Traditional treatment yes vs. no & 2.24 & {$[1.05-4.81]$} & 0.0365 \\
Platelet (G/l) $<150$ vs. $\geq 150$ & 4.74 & {$[2.17-10.71]$} & 0.0001 \\
Splenomegaly yes vs. no & 2.85 & {$[1.34-6.18]$} & 0.0070 \\
Jaundice yes vs. no & 1.72 & {$[0.80-3.86]$} & 0.1727 \\
Ascites fluid infection yes vs. no & 0.69 & {$[0.22-2.24]$} & 0.5260 \\
\hline
\end{tabular}

95\% CI: 95\% Confidence Interval; OR: Odds Ratio; SAAG: Serum-Ascites Albumin Gradient.

Table 4. Predictive factors of esophageal varices (multivariate analysis).

\begin{tabular}{ccccccc}
\hline & \multicolumn{5}{c}{ Initial model } & \multicolumn{3}{c}{ Final model } \\
\cline { 2 - 7 } & OR & $95 \%$ CI & p value & OR & $95 \%$ CI & p value \\
\hline Male vs. female & 2.03 & {$[0.76-5.47]$} & 0.1545 & 2.71 & {$[1.09-6.88]$} & 0.0321 \\
Albumin in ascites fluid (g/l) & 13.04 & {$[2.19-113.63]$} & 0.0084 & 12.77 & {$[2.71-94.24]$} & 0.0033 \\
$<30$ vs. $\geq 30$ & & & & & & \\
Child C vs. A and B & 1.32 & {$[0.47-3.63]$} & 0.5943 & & & \\
SAAG (g/dl) $\geq 1.1$ vs. $<1.1$ & 1.44 & {$[0.51-3.89]$} & 0.4790 & 1.63 & {$[0.63-4.15]$} & 0.3020 \\
Alcohol yes vs. no & 3.32 & {$[0.90-12.88]$} & 0.0727 & & & \\
Traditional treatment & 2.10 & {$[0.81-5.55]$} & 0.1270 & & & \\
yes vs. no & & & & & & \\
Platelet (G/l) <150 vs. $\geq 150$ & 4.97 & {$[1.96-13.50]$} & 0.0010 & 4.30 & {$[1.83-10.47]$} & 0.0010 \\
Splenomegaly yes vs. no & 1.37 & {$[0.50-3.64]$} & 0.5232 & & & \\
Jaundice yes vs. no & 2.07 & {$[0.77-5.89]$} & 0.1575 & & & \\
\hline
\end{tabular}

95\% CI: 95\% Confidence Interval; OR: Odds Ratio; SAAG: Serum-Ascites Albumin Gradient.

0.61 (Figure 1).

\section{Discussion}

\subsection{Limitation of Our Study}

The main limitation of our study is that the collection of data was retrospective, a source of bias related to this type of study, including missing informations in medical records.Some patients did not performed cytochemical analysis of ascites fluid, protidogramand UGF. The main reasons mentioned were the lack of financial means and or lack of access to UGF. This reduced the number of included cirrhotic patients in our study. The other limitation was the fact that 


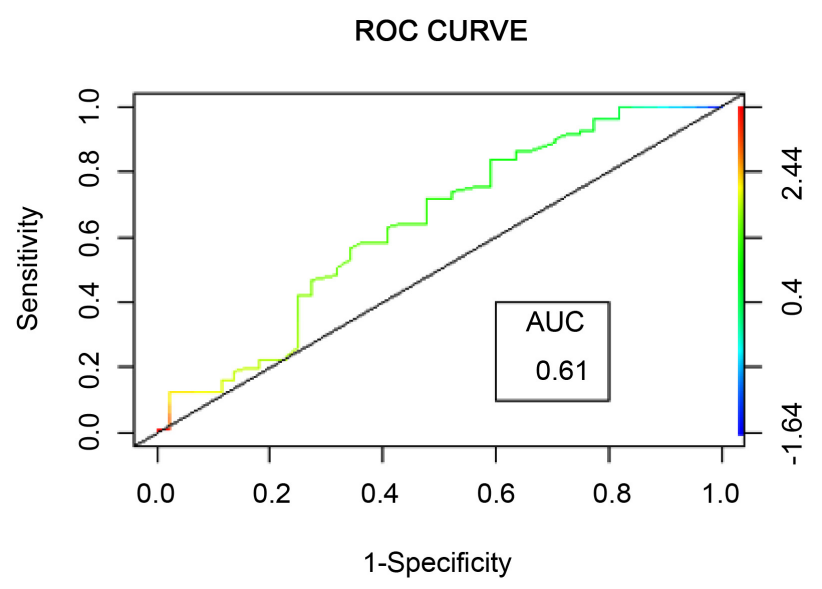

Figure 1. ROC curve corresponding to the evaluation of serum-ascites albumin concentration gradient (SAAG) in the diagnosis of esophageal varices.

cytochemical analysis of ascites fluid and protidogram were not always performed in the same laboratory and that also UGF was not always performed by the same operator. However, our study, the first one in Togo, a country with limited resources, keeps its interest because it enable us to investigate the existence of an association between SAAG and EV in cirrhotic patients with ascites.

\subsection{Serum-Ascites Albumin Concentration Gradient}

In our series, the median SAAG was $1.40 \mathrm{~g} / \mathrm{dl}$; the one found by Okon et al. in Ivory Coast [12] was $-0.30 \mathrm{~g} / \mathrm{dl}$. The majority of patients in our study had a SAAG high $\geq 1.10 \mathrm{~g} / \mathrm{dl}(65.6 \%)$ as in the studies of Gurubacharya et al. [14] in Nepal (78.13\%), and of Suresh et al. [15] in India (79\%). Shahed et al. [16] in Bangladesh had only included patients with high SAAG in their study. On the other hand, in the Okon et al. study in Ivory Coast [12], the majority of patients (68.2\%) had low SAAG. For these Ivorian authors, the condition of malnutrition of their patients causing hypoalbuminemia, and the infection of ascites fluid could explain the decrease in the value of SAAG.

\subsection{SAAG and Presence of Esophageal Varices}

Esophageal varices were significantly rated for SAAG high $\geq 1.10 \mathrm{~g} / \mathrm{dl}$. From a SAAG $\geq 1.50 \mathrm{~g} / \mathrm{dl}, 3$ out of 4 patients had significant EV. For Okon et al. [12], EV were significantly more prevalent in SAAG high $\geq 1.10 \mathrm{~g} / \mathrm{dl}$ (71.95\%) and were almost constant from SAAG $\geq 1.50 \mathrm{~g} / \mathrm{dl}$. In the work of Torres et al. [17], Demirel et al. [18], Suresh et al. [15], Gurubacharya et al. [14], and Shahed et al. [16], EV were consistently present in patients at the threshold of $2 \mathrm{~g} / \mathrm{dl}$. Apart from Shahed et al. [16] who did not include patients with low SAAG $<1.10 \mathrm{~g} / \mathrm{dl}$ in their study, none of the patients had EV at a low SAAG in the Torres et al. [17], Demirel et al. [18], and Gurubacharya et al. [14] studies contrary to the study of Okon et al. [12], and ours where the probability of presence of EV is not 
zero when the SAAG is low. Low SAAG $<1.10 \mathrm{~g} / \mathrm{dl}$ was not a parameter to rule out the existence of EV in our study; on the other hand, high SAAG $\geq 1.10 \mathrm{~g} / \mathrm{dl}$ significantly predicted the presence of EV.

\subsection{SAAG and Esophageal Varices Grade}

There is controversy over the correlation between SAAG and the size of varicose veins. In our study, no correlation was noted between SAAG and EV grade; it is the same in the study of Okon et al. in Ivory Coast [12]. Suresh et al. [15], Torres et al. [17], Gurubacharya et al. [14] and Demirel et al. [18] found a correlation between SAAG and the grade of EV. Shahed et al. [16] noted in their study that the increase in the value of SAAG correlated with the increase in the frequency of patients with grade III esophageal varices. On the other hand, this observation was not made in the case of grade I and II esophageal varices.

\subsection{SAAG and Other Signs of Portal Hypertension}

It was not noted in our study, an association between SAAG and the PHT gastropathy, the red signs on the EV and the cardio-tuberosity varices. Unlike our study, Okon et al. [12] observed that at a threshold of $1.50 \mathrm{~g} / \mathrm{dl}$ of SAAG, there were significantly $50 \%$ red signs, more cardio-tuberosity varices and gastropathy PHT. However, ivorian authors have not specifically identified a correlation between the level of SAAG and other PHT parameters [12]. Shahed et al. [16] noted that as the value of SAAG increased, so did the proportion of patients with severe PHT gastropathy; this finding was not made in the case of moderate PHT gastropathy.

\subsection{Predictive Factors of Esophageal Varices}

In multivariate analysis, being male, having a protein content of less than $30 \mathrm{~g} / \mathrm{l}$ in ascites fluid and thrombocytopenia, were the main predictive factors of EV. Patients with high SAAG $\geq 1.10 \mathrm{~g} / \mathrm{dl}$ were more likely to have EV. For Torres et al. [17], SAAG predicted EV from a threshold $\geq 1.435 \pm 0.05 \mathrm{~g} / \mathrm{dl}$.

\subsection{Diagnostic Performance of SAAG for the Prediction of Esophageal Varices}

The area under the ROC curve was 0.61 indicating a fairly good diagnostic performance of SAAG. Okon et al. [12] found 0.80; they had noted at the threshold of $1.10 \mathrm{~g} / \mathrm{dl}$ a Se of $53.3 \%$ and a Spe of $80 \%$. Suresh et al in India [15] found at the same threshold an Se of $81 \%$, a Spe and a PPV of $100 \%$. From 1.50 $\mathrm{g} / \mathrm{dl}$ of SAAG, Spe was $65.90 \%$ greater but $30.40 \%$ were false negatives (1/3 of patients who developed EV were not diagnosed by the SAAG method with this threshold). At a threshold value of $0.91 \mathrm{~g} / \mathrm{dl}$ of SAAG (Youden index) in the patients of this study; $10.40 \%$ of false negatives, or one tenth of patients with $\mathrm{EV}$, were not diagnosed. Okon et al. [12] found a Youden index of $-1.640 \mathrm{~g} / \mathrm{dl}$ with a Se of $96 \%$, a Spe of $55 \%$, a PPV of $70 \%$ and a false negative rate of $3 \%$. These 
different findings reflect the difficulty of accurately finding a threshold value of SAAG, which can be used to diagnose patients with EV.

\section{Conclusion}

Since SAAG measurement is simple, less costly, non-invasive and easily achievable, it can be used as a tool for indirect diagnosis of EV and to allow the setting up of an early prophylactic treatment in the regions of Togo lacking digestive endoscopy centers; this can help prevent cataclysmic gastrointestinal bleeding. However, the upper gastrointestinal fibroscopy remains the most effective mean of diagnosing EV.

\section{Conflicts of Interest}

No.

\section{References}

[1] Rye, K., Scott, R., Mortimore, G., Lawson, A., Austin, A. and Freeman, J. (2012) Towards Non Invasive Detection of Esophageal Varices. International Journal of Hepatology, 2012, Article ID: 343591. https://doi.org/10.1155/2012/343591

[2] Crott, R., Makris, N., Barkun, A. and Fallone, C. (2002) The Cost of an Upper Gastroduodenal Endoscopy: An Activity-Based Approach. Canadian Journal of Gastroenterology, 16, 473-482. https://doi.org/10.1155/2002/548616

[3] Mandeville, K.L., Krabshuis, J., Ladep, N.G., Mulder, C.J., Quigley, E.M. and Khan, S.A. (2009) Gastroenterology in Developing Countries: Issues and Advances. World Journal of Gastroenterology, 15, 2839-2854. https://doi.org/10.3748/wjg.15.2839

[4] Gines, P., Quintero, E., Arroyo, V., et al. (1987) Compensated Cirrhosis: Natural History and Prognostic Factors. Hepatology, 7, 122-128.

https://doi.org/10.1002/hep.1840070124

[5] Bosch, J., Abraldes, J.G., Berzigotti, A. and Garcia-Pagan, J.C. (2008) Portal Hypertension and Gastrointestinal Bleeding. Seminars in Liver Disease, 28, 3-25. https://doi.org/10.1055/s-2008-1040318

[6] Cottone, M., Sciarrino, E., Marceno, M.P., et al. (1983) Ultrasound in the Screening of Patients with Cirrhosis with Large Varices. British Medical Journal, 287, 533. https://doi.org/10.1136/bmj.287.6391.533

[7] Chalasani, N., Imperiale, T.F., Ismail, A., et al. (1999) Predictors of Large Esophageal Varices in Patients with Cirrhosis. The American Journal of Gastroenterology, 94, 3285-3291. https://doi.org/10.1111/j.1572-0241.1999.1539_a.x

[8] Garcia-Tsao, G., Sanyal, A.J., Grace, N.D. and Carey, W. (2007) Practice Guidelines Committee of the American Association for the Study of Liver D, Practice Parameters Committee of the American College of Gastroenterology. Prevention and Management of Gastroesophageal Varices and Variceal Hemorrhage in Cirrhosis. Hepatology, 46, 922-938. https://doi.org/10.1002/hep.21907

[9] Sarangapani, A., Shanmugam, C., Kalyanasundaram, M., et al. (2010) Noninvasive Prediction of Large Esophageal Varices in Chronic Liver Diseasepatients. Saudi Journal of Gastroenterology, 6, 38-42. https://doi.org/10.4103/1319-3767.58767

[10] Mahassadi, A.K., Bathaix, F.Y., Assi, C., et al. (2012) Usefulness of Non Invasive Predictors of Esophageal Varices in Black African Cirrhotic Patients in Côte 
d'Ivoire (West Africa). Gastroenterology Research and Practice, 2012, Article ID: 216390. https://doi.org/10.1155/2012/216390

[11] Moulion Tapouh, J.R., Njoya, O., Monabang Zoé, C, Moifo, B, Kowo, M. and Nko’o Amvene, S. (2015) Approche non endoscopique du diagnostic des varices œsophagiennes d'origine cirrhotique dans une population d'Afrique noire subsaharienne. Health Sciences and Diseases, 16, 1-5.

[12] Okon, A.J., Thot'o, A.S., N'dri, N., et al. (2015) Interest Serum-Ascites Albumin Concentration Gradient in the Diagnosis of Esophageal Varices in Cirrhotic African, Abidjan (Côte d'Ivoire). Journal Africain d Hépato-Gastroentérologie, 9, 85-89. https://doi.org/10.1007/s12157-015-0595-7

[13] Battaglia, G., Bocus, P., Merigliano, S., et al. (2000) Endoscopic Diagnosis and Classification of Varices of the Gastro-Intestinal Tract. Acta Endoscopica, 30, 537-554. https://doi.org/10.1007/BF03026171

[14] Gurubacharya, D.L., Mathura, K.C. and Karki, D.B. (2005) Correlation between Serum-Ascites Albumin Concentration Gradient and Endoscopic Parameters of Portal Hypertension at Kathmandu Medical College Teaching Hospital, Kathmandu, Nepal. Kathmandu University Medical Journal, 3, 327-333.

[15] Suresh, I. and Jagini, S.P. (2018) Correlation of Serum-Ascites Albumin Concentration Gradient and Endoscopic Parameters of Portal Hypertension in Chronic Liver Disease. International Journal of Advances in Medicine, 5, 159-163. https://doi.org/10.18203/2349-3933.ijam20180077

[16] Shahed, F.H.M., Al-Mahtab, M. and Rahman, S. (2016) The Evaluation of Serum Ascites Albumin Gradient and Portal Hypertensive Changes in Cirrhotic Patients with Ascites. Euroasian Journal of Hepato-Gastroenterology, 6, 8-9.

[17] Torres, E., Barros, P. and Calmet, F. (1998) Correlation between Serum Ascites Albumin Concentration Gradient and Endoscopic Parameters of Portal Hypertension. The American Journal of Gastroenterology, 93, 2172-2178. https://doi.org/10.1111/j.1572-0241.1998.00615.x

[18] Demirel, U., Karincaoglu, M., Harputluoglu, M., et al. (2003) Two Findings of Portal Hypertension: Evaluation of Correlation between Serum-Ascites Albumin Gradient and Esophageal Varices in Non-Alcoholic Cirrhosis. The Turkish Journal of Gastroenterology, 14, 219-222. 